Article

\title{
An Inquiry Into the Experience of the Dyslexic Transactional Analysis Psychotherapist
}

Jan Baker and Mark Widdowson

\section{Corresponding Author}

Jan Baker, 42 High Street, Broughton DN20 0JA, United Kingdom

Email: jan@therapyworks4u.co.uk

\begin{abstract}
Dyslexia causes difficulties in reading, writing, and information processing and is known to impair academic performance unless adaptations are made to the teaching and learning environment. This article explores some of the ways currently practicing transactional analysts who are dyslexic recall and understand their experiences from the earliest recognition of their difference in being dyslexic, through their training, and into their current work life. The authors have investigated the impact of having dyslexia on the training and practice of five transactional analysis psychotherapists using a qualitative approach. The participants were interviewed and the data analyzed using thematic analysis. The results indicate further research would be beneficial to facilitate a deeper understanding of the impact of dyslexia and to facilitate appropriate support for both trainees and qualified psychotherapists.
\end{abstract}

\section{Keywords}

Training; transactional analysis; teaching; learning; psychotherapy; learning difficulty; memory; dyslexia; shame; disability

Much has been written and many attempts made to define the impact of dyslexia on children's learning experiences. Several definitions reflect the diversity of the experience of dyslexia and vary in their level of detail. Broadly speaking, these either examine the specific learning/processing difficulties experienced by people with dyslexia or focus on the psychological impact of living with dyslexia.

NHS Choices (2018) put it this way:

Dyslexia is a common learning difficulty that can cause problems with reading, writing and spelling. It's a specific learning difficulty, which means it causes problems with certain abilities used for learning, such as reading and writing. ... It's estimated up to 1 in every 10 people in the UK has some degree of dyslexia. (Para. 1-4)

This definition distinguishes dyslexia from a learning disability, stating dyslexia does not affect intelligence and that reading and writing skills can improve with specific educational support.

Gerber (2012) explored the challenges faced by adults with learning disabilities and how they might best be served in adult education settings. He included dyslexia in this category and contradicted common perceptions that learning difficulties equal limited intelligence by saying that there is a section of people who have a learning disability along with a high IQ. It is encouraging to note that he acknowledges, therefore, that "one size does not fit all" because there are a wide array of inter-individual differences" (p. 31).

McLoughlin, Leather, and Stinger (2002) began to develop this understanding of the complexities of dyslexia:

Developmental dyslexia is a genetically inherited and neurologically determined inefficiency in working memory, the information processing system fundamental to learning and performance in conventional educational and work settings. It has a particular impact on verbal and written communication as well as on organization, planning and adaptation to change. (p. 19) 
The British Dyslexia Association (BDA) added possible cooccurring difficulties that may be present with dyslexia, such as aspects of language, motor coordination, mental calculation, concentration, and personal organization, which are not, by themselves, markers of dyslexia. They cited a report by Rose (2009) that said, "A good indication of the severity and persistence of dyslexic difficulties can be gained by examining how the individual responds or has responded to well-founded intervention" (p. 34).

In addition to these characteristics, the BDA acknowledged the visual and auditory processing difficulties that some individuals with dyslexia may experience and that they can show a combination of abilities and difficulties that affect the learning process. Some demonstrate strengths in other areas, such as design, problem solving, creative skills, interactive skills, and/or oral skills. Although specialist support programs existed that are designed to help people with dyslexia manage their own particular difficulties, accessing these can be difficult. It is recognized that these interventions are most effective when begun at a young age (NHS Choice, 2018).

The impacts of dyslexia in adulthood can be more intense and less acceptable or understood, and likely more so if the individual's dyslexia is undiagnosed such that the person has adapted or hidden his or her difficulties for many years. We have not located much literature that specifically examines the psychological and emotional impact of dyslexia in adults. From the literature that is available Moody (2014a) wrote this moving acknowledgment:

A patient or client [with dyslexia] reports the following: low self-esteem, lack of confidence, feelings of shame and embarrassment, inability to study or work efficiently, panic at the thought of going to the office, poor concentration, memory lapses, periods of blanking out in conversations, and difficulty in relating to people. (Para. 7)

She went on to say:

They [dyslexic adults] regard themselves as being "thick" or fundamentally flawed in some puzzling way. In these circumstances their difficulties can become a guilty secret - a source of humiliation. In the workplace there is also a fear that, if the difficulties become too evident to an employer or to colleagues, then promotion could be blocked or, even worse, dismissal ensue. (Para. 9)

Orenstein (2012) described ways people might experience the traumatic reality or threat of an original/early and difficult learning experience by using the acronym CHASM to represent feelings of:

$$
\begin{aligned}
& C=\text { Confusion } \\
& H=\text { Helplessness } \\
& A=\text { Alienation } \\
& S=\text { Shame } \\
& M=\text { Mind Freeze }
\end{aligned}
$$

She indicated that these feelings are often reexperienced in similar and subsequent environments (i.e., further education establishments, work settings, etc.), and in this research, there is strong evidence that they are found in the psychotherapy training process, professional practice, and beyond.

From a literature search, I (JB) found limited reference to the impact of dyslexia or experiences of education for adults returning to education in later life beyond acknowledgment that this might cause difficulties. To date, there has been no previously published research on the experience of dyslexia within the transactional analysis literature.

The present study was developed by me (JB) and evolved from my own experiences as someone diagnosed with dyslexia in adulthood during psychotherapy training. Specifically, I was curious not only about the practicalities of navigating through learning and life as someone with dyslexia but also how much this diagnosis would impact my life, others, and, specifically, my work as a transactional analysis psychotherapist. That is, I was interested in how my dyslexia might impact my work with psychotherapy clients.

I (MW) do not have dyslexia, but I have experience teaching and supervising numerous students who have been diagnosed with dyslexia over the years. I have often wondered how best they can be supported through the training process. As a psychotherapist, I have worked with a number of clients who have dyslexia and have been aware of the extensive impact that it has had on their lives. I have wondered how to conduct therapy in a way that enables these clients to get the most out of therapy. 
The challenges I (JB) faced when relating these stories have been both practical and emotional, and if the structure of the article is confusing or disjointed in places, this may give you, the reader, some sense of what these challenges look like. I hope they demonstrate how our individual challenges continue in our practices and daily lives. The risks we take to understand and be understood are real and intricate, and this study goes some way to showing what we know so far.

\section{Research Questions}

We were curious as to how the early developmental and educational experiences and later training experiences of the dyslexic psychotherapist impacted their current practice. Our study was aimed at answering four research questions;

1. How did having dyslexia impact the participants' development?

2. What were participants' early and later experiences of education and training?

3. What are the experiences of transactional analysis psychotherapy training like for adults with dyslexia?

4. What impact does psychotherapists' dyslexia have on their work?

\section{Method/Data Collection and Analysis}

A qualitative method was chosen in order to emphasize individual participants' lived experience and to encourage providing depth, detail, and expansion of responses. The research was conducted by the me (JB) with MW acting as research supervisor.

\section{Sampling}

Given the nature of the study, a purposive sampling strategy was chosen (Bernard, 2002). The following advertisement, inviting prospective participants to contact me (JB), was placed in the United Kingdom Association for Transactional Analysis (UKATA) quarterly magazine for members, The Transactional Analyst, and the British Association for Counseling and Psychotherapy (BACP) membership journal, Therapy Today: "I am looking for qualified, practicing Transactional Analysis (TA) psychotherapists who were diagnosed with dyslexia as adults to take part in a pilot study."

I chose to focus on TA psychotherapists specifically because they reflected most closely my own training experience. Both of us are of the view that transactional analysis provides a coherent framework for understanding thoughts, feelings, and behaviors (e.g., contaminations, script beliefs, drivers, etc.) that an individual might have relating to education. We also believe that TA can provide a clear framework for interventions that challenge thoughts, feelings, and behaviors that may limit an individual's engagement with education and learning (see Barrow, 2009).

From the 10 responses to the UKATA advertisement, five individuals expressed interest in consenting to and subsequently taking part in face-to-face interviews. All respondents were female. One of them had not had an official diagnosis, and one had been diagnosed at age 14. The remaining five did not meet more than two of the criteria or withdrew for personal reasons.

Because none of the nine BACP respondents met the criteria of being TA practitioners, I (JB) decided to focus on conducting the interviews with the five consenting participants from the UKATA advertisement and to offer the BACP group the questions used during interviews via email. I wanted to see if there were any similar responses arising in this group to corroborate the interview participants' answers and to explore whether there were indicators that therapists trained in another modality had similar or divergent experiences. The present study has analyzed the data from the sample of TA psychotherapists only.

A semistructured interview schedule was developed containing the following questions:

1. Are you professionally diagnosed and assessed as having dyslexia?

2. At what age were you diagnosed?

3. Are you a practicing psychotherapist and if so, what is your main modality?

4. What impact, if any, do you think dyslexia had on your early life?

5. Were either of your parents dyslexic? 
6. What support, if any, did you ask for/receive for your dyslexia: as a child/as a trainee psychotherapist?

7. If support was received, was it helpful?

8. What impact, if any, do you think dyslexia has on your work as a psychotherapist?

9. Is there anything else you would like to add that you feel might be relevant to this research?

\section{Data Collection}

Face-to-face interviews were conducted. These were audio recorded, and verbatim transcripts were made of these interviews for the purposes of data analysis.

\section{Data Analysis}

The data was analyzed using thematic analysis (Braun \& Clarke, 2006). This qualitative research method is versatile and suitable for use in initial exploratory research such as the study described here.

$\mathrm{I}(\mathrm{JB})$ recognized that I felt anxious about organizing the research and conducting the data analysis process. In line with recommendations for qualitative researchers (McLeod, 2011), I kept a reflective notebook in which to record my own process and personal experiences throughout the research project. This was to enable a degree of bracketing to take place between my personal lived experience and the data analysis process. We believe that it is impossible to truly separate oneself from the data analysis process: "We are biased by our own background, knowledge and prejudices to see things in certain ways and not others" (Walsham, 2006, p. 321). We also acknowledge that the researcher's own subjectivity can add considerable insight into the data analysis process.

Consequently, some aspects of my own reflections (thoughts, feelings, memories) have been included in the following results section. These have been labeled "Reflections" so that readers can distinguish between data gained from participants and data gained autoethnographically from the researcher's own reflections. The intention was to draw on my subjective experience as an additional data source but, at the same time, to be explicit about who that data was from. We hope this enables readers to see my subjectivity and in doing so, bring transparency to the data analysis process and presentation of findings.

The results section contains quotes relating to each identified theme taken directly from the transcripts of the research interviews. We have not changed or corrected the words or grammar used by the research participants so that the quotes will accurately represent the participants' experiences and reflect the challenges they faced and the courage they showed in telling their stories.

\section{Results}

From the data analysis, we identified four superordinate themes and twelve themes.

\section{Superordinate Theme 1: Difference and Shame}

Within this superordinate theme, we identified two themes. Both seemed to focus around issues of difference and shame. One was specific to educational settings and the other was related to an atmosphere of shame and things unspoken within families.

Theme: Disruption of Education. The experience of formal education was significant to all of the participants in the study. All experienced disruption to their education in school as a direct result of their dyslexia, which had a clear impact on their attitudes toward education and themselves as learners.

One participant spoke of disruption to her secondary school education due to many absences because of physical illness, which led to a missing of her needs and a lack of formal assessment or diagnosis of her dyslexia. In primary school, there had been some recognition of difference, but it was often clumsily managed by segregating her from mainstream classes and placing her into special classes. Despite this early recognition, because of her prolonged absences, this support was not followed up further during her schooling until she sought and pursued at length an official assessment and diagnosis in adulthood.

All the participants talked about how they felt different from their classmates, which was a feeling they carried into adulthood. They described reconnecting to this feeling and felt a sense of being different in adult life in educational settings, for example, when they trained as nurses or psychotherapists. Here are some examples: 
- "Isolating. When I reflect now, I'm aware of feeling sad and it's quite emotive for me. It feels, I was constantly asking myself why, why am I like this and why am I not normal? Why can't I just do stuff? Why are these things hard work?"

- "We'd read a line from a story book, and it would just take me so long, and I'd be holding my finger, trying to keep on the line and it just felt so disjoined. I was really aware of the difference of the pace that I was going at to the other classmates. So, yeah, mainly about that difference, feeling different."

- "I felt different and frustrated a lot of the time. Not being able to articulate what I was holding in my head down to paper was just so frustrating and watching other people sometimes just doing so fluidly. I was quite envious."

- "Initially, what was really interesting, I always used to say I loved school. I had a really happy time at school but I really didn't because, again, I had completely cut off all the humiliation. I can touch it now ... yeah. So, yeah, education trauma."

- "I was the naughty child? I think it was because they put it down to me not spending enough time doing something, that I wasn't achieving what I was capable of. So, again, I think it's the discrepancy between writing and being articulate, wasn't really understood or that scrutiny just wasn't in the mix."

These narratives highlight issues associated with isolation, shame, humiliation, and misunderstanding that were a part of educational experiences for the participants. And from the participant who has not been assessed or diagnosed:

- "I just think why hasn't this happened, why have I not been assessed, you know? I'm 55. I went to seven different schools because of my parents disagreeing, separating, divorcing, moving, and I think probably what happened was I just kind of held on in my education rather than, and I didn't do badly, I mean I got two A Levels, the first time around, I got a B and an E. ... I redid my English which was an E, and I got a C, so I still couldn't get a high grade in English." (Participant later talked of how she was aware of talking in a "disjointed" way during our interview.)

- JB Reflections: "I was also aware of doing this and felt a real connection with her as I have experienced this feeling many times in conversation."

Another participant was directed to an assessment at her comprehensive school by a teacher who had some knowledge in the area of dyslexia:

- "I just thought, it was quite, I was quite conflicted actually because I didn't feel that I wasn't intelligent. I felt like I was fairly bright in some respects but I just was very slow at everything, slower than everybody at reading, slower at comprehending and writing ..." (Interviewer): "Because it isn't anything to do with intelligence ..." "Obviously, I didn't know anything different so, I just didn't really understand what was going on, and yeah, I think it affected my self-esteem a lot."

So, although this recognition elicited some practical help, it often provoked further feelings of isolation, widening the gap of "feeling different:

- "There was nothing in the school at all, but he, (a teacher) used to stick me in a taxi and send me to another local school that was running a new scheme for dyslexic students, where you go for a couple of hours and they teach you different ways of learning different to everybody else. And I remember just thinking oh, I'm the special kid, when I was, and making me feel a bit worse really."

- JB Reflections: My sense of isolation was not provoked by physical segregation as my dyslexia had not been recognized at that time. I experienced a felt sense of being in the company of others who spoke in a way I often 
didn't understand, nor they me. I would often get instructions wrong and miss out on what everyone else in the class was doing.

It is clear that not only did these experiences shape the participants' script beliefs around education and learning but also contributed to a more pervasive sense of being different, of not understanding things in the same way as others, and of a lasting sense of shame that resulted.

Theme: Shame in the Family. Three participants reported a shared sense of shame throughout their family about their dyslexia and problems with literacy that were unspoken. This was overlooked or not acknowledged at home by parents. A number of the participants reported having a felt sense that one or both of their parents were dyslexic, and it was not until later in their (the participants') lives that this was confirmed. So, it was possible that the sense of shame and isolation began to develop within the family. There was an ulterior message being delivered, an incongruence: "This is something we don't talk about in this family."

- "Both of my parents are dyslexic. Well, my dad was illiterate, and so he'd be reading books, but then I realized after a bit that he's not reading the words, he was reading the pictures to me."

- "I guess there was awareness and probably some understanding but not really support. It was almost like it's just how it is but not [some] sort of explanation because, of course, no one knew how to explain it, no one understood the intricacies."

- "My mother has never really achieved anything academically. ... She'll say, 'I'm no good at maths, and I'm useless at this and my brain goes dead at anything mathematical."

- "My dad was evidently dyslexic, and again, was never diagnosed." (Interviewer): "I don't ever remember hearing the word [dyslexia] until I was well into my teens." "No, and that was what was interesting. My mum, funny enough, is a teacher, but she trained later in life as a mature student. And I think she was aware of dyslexia, and I think she knew, because my elder brother was also dyslexic, and it wasn't until I left school and I didn't have any GCSE's or a few? And my parents got me a tutor to help me with maths and English when I was at college and it was a tutor that said 'Oh, I think you're dyslexic.' '

- "[My father], he's very good at maths, and I think he's that way inclined. He loves things like jazz and he loves art but he said he struggled with English and he wonders if it was because [his father], he struggles with reading, he does. He doesn't really read."

- JB Reflections: "Looking back, I think my Mum might have had a form of dyslexia. Often with her it was like we spoke a different language, "missing" each other and hearing different information. I think it was more than the usual child/parent misunderstanding. I struggle with the concept that dyslexia is all 'nature' as it takes so many differing forms."

\section{Superordinate Theme 2: Creative Strategies for Developing Resilience}

Theme: Developing Resilience in Childhood. Here are some comments on this theme:

- "And so, I kind of channeled my creativity, and when I went back to school, which was literally the last year, I took my GSCEs. And I was like, I'm going to sit down in this hall and I just did it. And I got a C in English, a D in maths, and more or less ungraded in the rest. But to have achieved those, [even with] the lack of school and the dyslexia, I thought there's something there."

One participant described how her resistance to labeling triggered a sense of resilience:

- "It helped in as much as I was then really stubborn, it helped in terms of there's nothing wrong with me, and I'll prove to the world that there's nothing wrong with me and no I'm not dyslexic. So, it helped because actually it 
gave me an enormous amount of energy and an enormous amount of confidence to go out and do what I wanted to do. So, it didn't help in a traditional sense of oh, that explains it, it went the other way in as much as I'm not having that, I'm not having a label thank you very much, I'll prove to you all that I'm not because for me, it felt as if that was something wrong, as if that was a bad thing to have."

- JB Reflections: “I clearly felt I couldn't keep up with classwork and rarely put up my hand to answer a question for fear of humiliation as I had usually misunderstood it. We had a school trip to a nature reserve, and I recall spending hours learning beforehand how to identify the names of many wild flowers. I experienced a sense of pride, that I could get something right, as I overheard the teachers praising my knowledge with amazement."

Theme: Developing Resilience in Adulthood. Here are some examples:

- 'I felt like it was really important for me to do it on my own really. I don't know why. I didn't push for support. It wasn't offered but I didn't push, I didn't ask."

- "I was good at sport, so for me that was my sanctuary because I could shine at sport, and I could hide away from everything else because that's how I sort of survived."

- JB Reflections: "Now I am comfortable mostly to ask for what I need to help me manage, that is, printed sheets rather than struggling to mark an exam on the computer screen. However, every now and then I experience the pain of shame for asking, for feeling different, for having needs, of the Child fantasy that others can cope."

\section{Superordinate Theme 3: Ambivalence Around the Dyslexic Label}

The study participants spoke about their ambivalence toward the diagnosis of dyslexia. Although receiving the diagnosis was in some ways a relief and helpful, in others it represented a marker of being different and of something to fight against.

Theme: Diagnosis and Assessment. Here are some examples:

- "I haven't really thought about it as being dyslexia. Because I haven’t had a proper test."

The urgency of seeking a diagnosis, almost as a form of validation, was important and reflected movingly in one participant's experience as she described how the assessment she had done, at aged 20, was lost. She went to great lengths to find it so she could prove what she needed to support her through her psychotherapy exam.

- “I've known all my life but I wasn't diagnosed until I was in my second year at college [TA training], so I was 49. It was done privately, and it was through my own curiosity. College didn't offer it to me, and they didn't suggest [it], but I just felt it would be really helpful to know one way or the other. But I'd already been at college for a year, and I guess learning about TA and script and I was then really interested. I really wanted to find out if this is a reality or if this is something I was told, learned? I wanted some confirmation."

- "The ownership I think ... this certification of this is what's wrong with you, get on with it."

- "I was really surprised at the impact it had. So, I took that to therapy a lot because I think initially it was a relief but also I think it was then actually a lot of loss and grief, as in wow, I'm coming to terms with that too because I think for so long I always thought there was something wrong with me, and I didn't know how that fitted. So, it was a double-edged sword really, because it was a relief to think OK, there's there is something, you know, that is difficult for me. But yes, it brought up all sorts [of things]. So yeah, it stirred up a lot."

- JB Reflections: "I am reminded of the definition of pain as learned in my previous nurse training, which is 'whatever the experiencing person says it is, existing whenever the experiencing person says it does" " (McCaffery, 1968, p. 95). If a physical disability is present, such as deafness, and the person asked you to speak up or be clearer, there would be no questions about this. I understand the desire versus resistance for a formal 
diagnostic assessment in a similar way to how Fowlie (2005) described relational expectations when a client comes for therapy - both the 'longed for' (in recognition of difference) and the feared (that the difference might not be accepted)."

Theme: Disability: Recognizing One's Own Strengths and Limitations. Here are some examples:

- "That's a really good question. I guess if I'm honest, yes, but I fought that, I fought it all my life, that there's a disability. Because of the connotations I guess, as if again, there's something wrong with me as opposed to for me. And, I guess, it's also given me lots of advantages and maybe in other areas. So, I like to think it's given me some strengths as opposed to what it hasn't given me. I've kind of skimmed over that, I think more."

- "So, but I kind of, I keep pushing it out of my head, and I don't see it as a disability whereas actually, it probably is a disability and now, as I'm talking to you ..."

\section{Superordinate Theme 4: Impact on Therapeutic Relationship/Client Work}

Within this superordinate theme, we identified six themes that highlight that participants' dyslexia has had a broad-ranging impact on their professional lives.

Theme: Impact on Being Misunderstood/Understanding. Several participants spoke about their concerns around expressing themselves and being misunderstood by clients.

- "One client springs to mind who I was working with for about 9 or 10 weeks. And she experienced me as not getting her. And that's true, I didn't. So, whether that's the process of dyslexia or whether it's the therapeutic unconscious process being activated in some way? And she didn't stay to find out."

The participant who had not been officially diagnosed or assessed reported the least impact on her work:

- "What I try to do is be as clear as possible when I'm speaking to a client, like, not ask too many questions, but sometimes I think I might go round about the houses to try and explain what I mean. And I'm conscious of that sometimes."

Theme: Impact on Intuition and Creativity. Several participants who spoke about developing their creativity in childhood as a means of coping with their dyslexia and their feelings around it had found ways of using this resource in their work with their clients.

- "I would say I am incredibly intuitive. Again, I think it's, I've always struggled to put that into any kind of wording or what that means but I learnt, and I think this is because of my dyslexia. I learnt to read people from a very early age. And I wonder how much that was my dyslexia, how much was that kind of script looking to, again, how I needed to be with people and looking to kind of, yeah, how do I fit, how do I keep them happy?"

- JB Reflections: "I am aware I work with clients in a very intuitive way. I think this is because I trust my intuition to compensate for my perceived shortfalls in my understanding of the spoken word."

Theme: Impact on Writing and Note Taking. All the participants spoke about issues associated with the administrative tasks in clinical practice. Routine note keeping was often a laborious, tiring, and time-consuming process.

- "So, to write my notes on clients, it takes me a long time and I'm always very, I'm very slow and I try to be very succinct. For my own notes, my own processing notes, they probably make no sense to anyone and even to myself sometimes ... if anyone was to pick up my own process notes and look at them, they would struggle to have any understanding."

- "I'm also a really slow typer because I find it really difficult to go from paper to screen and screen to paper." 
One participant spoke of how she had spent considerable time developing a pro forma to assist with her note keeping and yet still found administrative tasks time consuming:

- “[Writing] takes me forever, and I like to have lots of templates and ideas. So, even now I don't ever just trust myself just to write. So, emails, I'll read them quite a few times before I send them. But I'm not the greatest proof reader, so the irony in that is well, I'm not going to spot, probably, that I've made an error anyway."

Theme: Impact on Self-Confidence and Taking Time. Several participants described how they have developed the confidence to deliberately pause, slowing down to allow them to process information. However, they can sometimes be taken by surprise, which can lead them to feeling shame.

- "The other area of difficulty I've noticed in the therapy room is if people ask me a question, I have to stop. And again I'm aware that actually sometimes that might be because of my experience, my educational stuff. Of being kind of caught out or oh, I don't know the answer, so I'll go to that immediate panic place of oh, I don't know the answer ... So, I know to give myself time, but again, that's in my more recent learning."

Theme: Impact on Memory. Issues associated with information processing and memory was a feature of dyslexia that was problematic in the training and continuing professional development for several participants.

- "I can read a book and think oh gosh, this is so interesting, and I think this is so amazing, it absolutely astounds me, well, why don't I then remember that? Because I was so engrossed in that, I was so interested in that, take it away, I couldn't tell you what was in there. I couldn't tell you anything about it."

Theme: Impact on Organization. Some participants spoke about finding tasks around organization to be challenging.

- "I miss things in my diary, so I have to be very careful not to double book people, or to book people in times when I'm not there ... that whole organizational part of this job... I do find if I'm feeling any kind of permanent stress or busyness, I get, like, a dyslexic fog. Where I just can't connect with what's going on and feel lost really."

\section{Additional Results: Exploring the Impact of the Research Process}

When starting to collate the findings of the research, I (JB) became curious about how the participants might be reflecting on the interviews and if there was more they wanted to add. I though perhaps after telling their stories, some for the first time, and becoming immersed in the interview process, they might have further comments. Or, I thought perhaps they might have been reluctant to disclose difficulties experienced in their work, from one psychotherapist to another, given the short time available to build a trusting relationship during the interviews. I considered how this reluctance can be a feature in clinical supervision, that is, the hiding of perceived errors of misunderstanding due to shame. Perret (2017) wrote, "Learning situations, including supervision, are places that are conducive to the awakening of shame" (p. 44).

To check out my thinking on all of this, I emailed participants several months later inviting them to , to the interview participants, and received the following, from two participants:

"My reflections following the interview were that I felt proud of myself in what I've achieved through and with my dyslexia. Sitting and talking this through in the interview helped me to connect with the struggles and breakthroughs I've had in my life concerning my dyslexia. I connected with my physis and utter determination which is inherent in me. ... On reflection I feel dyslexia is present in my practice as I may work things out in a different way or order to a nondyslexic person. This can at times cause misunderstandings and therefore at times crossed transactions. This can impact on slight disconnect, which I hope to reconnect with the person."

"I realized your request evoked a fear of getting something wrong/not giving you what you needed/wanted and my response was to procrastinate in replying. ... My working memory is poor and so I rely on my felt sense to understand what the client is communicating. In the moment I am totally present but after a session I find it 
difficult to recall and need time to let the session settle. I will not remember word for word what the client said but my 'felt sense' is accurate when I then listen back to my recordings. From a very early age I became very astute to people's moods and feelings and so I use transference and countertransference to understand what maybe playing out in the room. I often will know something 'big' is happening but I find it difficult to find the words to explain it. ... (Perhaps that is normal TA stuff.) My other thought is how difficult I find it when I am asked something (evidence of your request!). My fear of not being good enough or getting something wrong still hovers around but I realize I just need time to process. Something with education and personal insight I now understand and I am much more gentle with myself."

JB Reflections: "I am aware in producing this piece that I pay an enormous attention to detail as I put it together. I find it challenging, as I did when I wrote my dissertation, to freely write, without constantly backtracking to check the layout, spelling, etc., as I go along. It feels like 'Be Perfect Driver' behavior (Kahler, 1974).”

\section{Discussion}

We note that this is an initial exploration of the issues faced by TA therapists with dyslexia and, as such, that there are clear limitations to this study. Specifically, the sample size was small, and all participants were UK-based transactional analysis psychotherapists, thus limiting the generalizability of the findings. Despite this, we recognize that this is the first study to explore issues associated with dyslexia among people in the TA community. As an initial inquiry, this research has opened up a broad range of issues that we hope will be explored more fully in future studies.

The issues of shame and difference highlighted in the first superordinate theme seem to have been particularly significant for our participants and not only shaped their educational experiences but also had an impact on their sense of self.

The second superordinate theme of creative strategies for developing resilience highlights how our participants developed their own ways of dealing with their specific difficulties. These seemed to center around creativity and increasing their efforts. Through a process of adapting to their dyslexia by "trying harder," it is possible that the adaptation process has potential implications in terms of the development of a "Try hard" process (Kahler, 1974).

The issue of shame and difference was revisited to some extent in superordinate theme three, which explored some of the ambivalence participants had about formal dyslexia diagnoses. On the one hand, a formal diagnosis of dyslexia provided answers about why the individual was struggling educationally (and in some cases meant that specific support was provided), but on the other, accepting a diagnosis confirmed that these individuals were different and also brought with it a fear that others would take pity on them and that as a result, their achievements might actually not be theirs but due to others feeling sorry for them.

In superordinate theme four, participants identified numerous ways in which their dyslexia impacts their professional practice. Some of these suggest adjustments that might be beneficial to trainees with dyslexia.

\section{Supporting Trainees With Managing in Training and Placements}

It was noted that several of the creative coping strategies that participants had established in childhood were developed further to manage difficulties they experienced during their training. However, these strategies were often covert in nature for fear of repeating the shaming experience(s) of asking for help. The participants outlined a number of reasonable adjustments that either did or would have helped them to manage the demands of the training process. These fall into (overlapping) categories of practical considerations and acknowledgment, nonjudgmental acceptance, and understanding, including the following:

- Requesting verbal and face-to-face communication rather than written as much as possible

- Appropriate and timely supervision

- Help with organization/appointments

- Technical support

- More time to complete tasks

- Self-disclosure when appropriate

- Asking for help offered without being singled out/segregated 
- Use of visual sources, especially three-dimensional aids (such as pictures) as well as metaphors

- Auditory aids, such as consent to record sessions, to make notes

- Access to short articles and instructions with less complex detail

- Permission to think creatively

- Learning strategies that promote retention and recall of material/memory aids

It is important to recognize that not only can it be hard for trainees with dyslexia to ask for help but that they may be concerned that they will be shamed or pitied. We add a quote from one of the research participants who expressed some of the internal struggles that a trainee with dyslexia might experience.

- "So, I did highlight it because I thought it would be useful, and they advised me to always write at the top of my essays, "Please be aware I am dyslexic." I really struggled with that because I felt it was almost, I then discounted everybody and myself thinking oh, they'll give me special favors, as if, you know? And I hated that, I hated kind of to be different or to be given anything that might go against my own ability. I always want to make things twice as hard for myself to kind of almost prove to myself that I am capable. So, I hated the thought that actually, I might get a favor, well, they'll only pass me because I've written I'm dyslexic. So, yeah, I didn't like it. So, that's the only support I would say, or advice that they gave me."

In light of this, we encourage trainers and supervisors to make it clear that although they are accounting for a trainee's dyslexia, that does not mean that academic standards are being watered down for that person. Rather, support is aimed at removing some of the disadvantage that the trainee with dyslexia has with regard to his or her training process. We also encourage trainers and supervisors to build activities into sessions that provide opportunities for all trainees to clarify their understanding of the topic being discussed, without trainees with dyslexia feeling singled out.

The need for a formal professional diagnostic assessment is currently the key to getting support throughout TA psychotherapy training to examination.

- JB Reflections. I felt there were unmet emotional needs in my training experience. One way of understanding this is to consider the possibility that in the person with dyslexia, the process of ongoing healthy attachment and connection with others may be disrupted or partly excluded. I see this particularly when considering the relational needs identified by Erskine, Moursund, and Trautmann (1999) for security (to be yourself and trust without being ridiculed or shamed), for validation and meaning (to be recognized, acknowledged, and understood), for acceptance (of a stable, reliable, protective other), to gain encouragement and information (from parents, educators, etc.), and for mutuality (shared experiences and to fit in).

\section{Conclusion: Implications for Practice, Research, and Education}

Dyslexia is significantly misunderstood. Dyslexic children become dyslexic adults. This study supports, extends, and challenges existing research and literature and contributes to our understanding of the impacts of dyslexia on people diagnosed as adults. It considers how challenges that begin in childhood persist and develop in later life to impact the psychotherapeutic relationship. We hope that exploring these experiences may contribute to the practice of psychotherapy by facilitating understanding in employers, training establishments, and other therapists about what it means to be a person with dyslexia.

The findings have implications for the education of transactional analysts more broadly. We hope that supervisors, trainers, universities, colleges, and training establishments consider the recommendations made in this article and reflect on how they might provide some of the range of accommodation needed to assist psychotherapists (or transactional analysts in other fields) with dyslexia in managing their training and practice. Therapists with dyslexia are a rich, creative, and insightful group of potential educators, supervisors, and professionals who can serve as models for trainees and clients with and without dyslexia.

Further research into dyslexia could offer training establishments and workplaces the information they need to be able to accommodate the individual learning needs of the dyslexic trainee from intake through to qualification and beyond in all four fields of transactional analysis. We invite trainers and supervisors to consider how their methods might be experienced by a trainee with dyslexia and whether or not those methods might benefit from some 
adjustments. We also invite trainers and supervisors to engage trainees who have dyslexia in discussions to establish if they need any additional support or adjustments to provide them with a learning experience that might more closely meet their needs.

In our study, it emerged that there was considerable overlap in experiences identified by both BACP and UKATA respondents. We note that the similarities in accounts suggest further research with therapists of other modalities is warranted. Providing more funded personal therapy and supervision with therapists/supervisors who are aware of and/or specialize in dyslexia as well as facilitating discussions to remove stigma and prejudices are just two ways this might be achieved. The TA community has the grounding to do this with its philosophy of "I'm OK, You're OK" (Stewart \& Joines, 1987 ) to facilitate understanding and lead the way to acceptance of all who choose to be part of the profession.

We found this quote from one of the participants to be particularly poignant. We invite readers to reflect on it and hope it may spark some discussion within TA organizations about our training and examination processes. In particular, we invite a deeper reflection on the level of recognition and understanding of the specific difficulties experienced by trainees with dyslexia and also how our training and examination systems can be adjusted to make them more inclusive and accessible.

"I found particularly in the TA arena that if I asked for some support with something, people are generous. But it's just something about the mismatch between generosity of spirit of people in this arena and then the requirements of the organization and this is how it is and it's quite rigid. That's the incongruence I think and really I found that difficult. ... I could just see him looking at me as though to say, you know, you're coming up with some story or you're trying to hook us into some sort of game here. 'The dyslexia card.' And I, yeah, so I suppose I felt really pissed off [laughs]. Really, I really felt a sort of deep sense of injustice, yeah.”

\section{Disclosure statement}

The author declared no potential conflicts of interest with respect to the research, authorship, and/or publication of this article.

\section{Funding}

This study was partially supported by a research grant awarded by the United Kingdom Association for Transactional Analysis.

\section{Acknowledgment}

The first author (Jan Baker) expresses her gratitude to all those who contacted her for their willingness to share their experiences.

\section{Notes on Contributors}

Jan Baker, MSc (P), CTA (P), Dip. TA Supervision, is a Provisional Teaching and Supervising Transactional Analyst (psychotherapy) and a UKCP registered psychotherapist.-She has a private clinical and supervision practice in North Lincolnshire, United Kingdom. She can be reached at 42 High Street, Broughton DN20 0JA, United Kingdom; email: jan@ therapyworks4u.co.uk.

Mark Widdowson, $\mathrm{PhD}, \mathrm{MSc}$, ECP, FHEA, is a Teaching and Supervising Transactional Analyst (psychotherapy) and a UKCP and European Association for Psychotherapy-registered psychotherapist. He is the author of Transactional Analysis: 100 Key Points and Techniques and Transactional Analysis for Depression: A Step-By-Step Treatment Manual and is an active psychotherapy researcher. Mark is also a senior lecturer in counseling and psychotherapy at the University of Salford. He can be reached at Room 348, Mary Seacole Building, School of Nursing, Midwifery and Social Work, University of Salford, M6 6PU, United Kingdom; email: m.widdowson@salford.ac.uk. 


\section{References}

Barrow, G. (2009). Teaching, learning, schooling, and script. Transactional Analysis Journal, 39, 298 -304. [PROVIDE DOI] (https://doi.org/10.1177/036215370903900405)

Bernard, H. R. (2002). Research methods in anthropology: Qualitative and quantitative methods (3 ${ }^{\text {rd }} \mathrm{ed}$.). Walnut Creek, CA: AltaMira Press.

Braun, V., \& Clarke, V. (2006). Using thematic analysis in psychology. Qualitative Research in Psychology, 3(2), 77-101. [PROVIDE DOI] (http://dx.doi.org/10.1191/1478088706qp063oa)

Erskine, R. G. (2001). Psychological function, relational needs, and transferential resolution: Psychotherapy of an obsession. Transactional Analysis Journal, 31, 220-226. [PROVIDE DOI]

(https://doi.org/10.1177/036215370103100403) [ADD TO TEXT OR I'LL DELETE HERE] PLEASE DELETE

Erskine, R. G., Moursund, J. P., \& Trautmann, R. L. (1999). Beyond empathy: A therapy of contact-in-relationship. New York, NY: Brunner/Mazel.

Fowlie, H. (2005). Confusion and introjection A model for understanding the defensive structure of the parent and child ego states. Transactional Analysis Journal, 35, 192-204. [PROVIDE DOI] (https://doi.org/10.1177\%2F036215370503500209)

Gerber, P. J. (2012). The impact of learning disabilities on adulthood: A review of the evidenced-based literature for research and practice in adult education. Journal of Learning Disabilities, 45(1), 31-46. [PROVIDE DOI] (https://doi.org/10.1177/0022219411426858)

Jelly, C. (2014, 20 May). Are students with dyslexia supported in their nurse training? Nursing Times. Retrieved from

https://www.nursingtimes.net/students/are-students-with-dyslexia-supported-in-their-nurse-training/5070792.article [ADD TO TEXT OR I'LL DELETE HERE] PLEASE DELETE

Kahler, T. (with Capers, H.). (1974). The miniscript. Transactional Analysis Journal, 4(1), 26-42. [PROVIDE DOI] (https://doi.org/10.1177/036215377400400110)

McCaffery, M. (1968). Nursing practice theories related to cognition, bodily pain, and man-environment

interactions. Los Angeles, CA: University of California at Los Angeles Students' Store. (Los Angeles, University of California Print. Office, 1968)

[WAS THIS PUBLISHED? YES OR MAYBE PRESENTED? NEED FULL PUBLICATION INFO OR DAY/MONTH OF PRESENTATION ALONG WITH SPONSORING GROUP]

McLeod, J. (2011). Qualitative research in counselling and psychotherapy ( $2^{\text {nd }}$ ed.). London: Sage.

McLoughlin, D., Leather, C., \& Stinger, P. (2002). The adult dyslexic: Interventions and outcomes. London: Whurr.

Moody, S. (2014a). Dyslexia and dyspraxia in adulthood: Information for doctors and psychotherapists. Retrieved from http://www.lse.ac.uk/intranet/LSEServices/disabilityAndWellBeingService/Staff-Guides/PDFs/dyslexiaDyspraxia Adulthood.pdf

Moody, S. (2014b). Dyslexia, dyspraxia, and ADHD in adults: What you need to know. British Journal of General Practice, 64(622), 252 [IS THIS ONLY ONE PAGE LONG? YES IF NOT, GIVE INCLUSIVE PAGES]. [PROVIDE DOI] DOI: 10.3399/bjgp14X679859

[ADD TO TEXT OR I'LL DELETE HERE] (PLEASE DELETE AS USING 2014a?)

NHS Choices. (2018). Overview: Dyslexia. Retrieved from https://www.nhs.uk/conditions/dyslexia/

Orenstein, M. (2012). Smart but stuck: Resilience with learning disabilities ( $3^{\text {rd }}$ ed.). Oxon, England: Routledge. Perret, V. (2017). Shame, the scourge of supervision. International Journal of Transactional Analysis Research \& Practice, 8(2), 41-48. [PROVIDE DOI] (DOI: 10.29044/v8i2p41)

Rose, J. (2009). Identifying and teaching children and young people with dyslexia and literacy difficulties. Retrieved from http://www.thedyslexiaspldtrust.org.uk/media/downloads/inline/the-rose-report.1294933674.pdf

(Stewart, I \& Joines, V (1987) TA Today: A New Introduction to Transactional Analysis; Lifespace Publishing (IP))

Velde, B. P. (2000). The experience of being an occupational therapist with a disability. American Journal of Occupational Therapy, 54, 183-188. [PROVIDE DOI] (https://pdfs.semanticscholar.org/5ce8/2332cdd25cf861e310dab201ed2a08d2d133.pdf) [ADD TO TEXT OR I'LL DELETE HERE] (PLEASE DELETE)

Walsham, G. (2006). Doing interpretive research. European Journal of Information Systems, 15, 320-330. [PROVIDE DOI] (http://dx.doi.org/10.1057/palgrave.ejis.3000589) 
Young Kong, S. (2011). The emotional impact of being recently diagnosed with dyslexia from the perspective of chiropractic students. Journal of Further and Higher Education, 36(1), 127-146.

doi:https://doi.org/10.1080/0309877X.2011.606898. Retrieved from

https://www.tandfonline.com/doi/abs/10.1080/0309877X.2011.606898 